\title{
Sind Sie in guten (Treu-)Händen?
}

FMH Treuhand Services - Marktführer im Ärztetreuhand

Sie suchen Unterstützung bei der Praxisgründung, -führung oder bei einer allfälligen Nachfolgeregelung? Sei es die Ausarbeitung eines Businessplanes, die Buchführung, der Jahresabschluss, die steuerlichen Aspekte oder die Revision, unsere Treuhandspezialisten bieten Ihnen Lösungen nach Mass. In allen drei Sprachregionen sind wir zu Hause und kennen die regionalen und branchenspezifischen Gesetzmässigkeiten ganz genau.

\section{Unsere Dienstleistungen sind vielseitig}

Finanz- und Rechnungswesen

- Businessplan, Finanzplan

- Liquiditätsplanung

- Buchführung

- Abschlussberatung und -erstellung

- Kreditoren- und Debitorenbuchhaltung mit Mahnwesen

Analysen

- Analyse der Finanz- und Ertragssituation bei finanziellen Problemen

- Interpretation des Praxisspiegels (TrustCenter)

\section{Steuern}

- Erstellen von Steuererklärungen

- Steuerberatung und strategische Steuerplanung
- Finanzierungsmöglichkeiten

- Investitionsrechnung

- Personaladministration und Lohnbuchhaltung

- Abrechnungen mit Sozialversicherungen

Vertrauen Sie unserem breitabgestützten Netzwerk an Spezialisten.

\section{Antworttalon}

Vorname / Name

Adresse

PLZ / Ort

Telefon privat/Geschäft

Beste Zeit für einen Anruf

(ø) Ich interessiere mich für das

Dienstleistungsangebot FMH Treuhand Services.

Bitte nehmen Sie mit mir Kontakt auf.

- Beratung in Mehrwertsteuerfragen

- Erstellung der Mehrwertsteuerabrechnung 